\title{
Whole-genome mapping identified novel "QTL hotspots regions" for seed storability in soybean (Glycine max L.)
}

\author{
Xi Zhang ${ }^{\dagger}$, Aiman Hina ${ }^{\dagger}$, Shiyu Song, Jiejie Kong, Javaid Akhter Bhat ${ }^{*}$ and Tuanjie Zhao ${ }^{*}$
}

\begin{abstract}
Background: Seed aging in soybean is a serious challenge for agronomic production and germplasm preservation. However, its genetic basis remains largely unclear in soybean. Unraveling the genetic mechanism involved in seed aging, and enhancing seed storability is an imperative goal for soybean breeding. The aim of this study is to identify quantitative trait loci (QTLs) using high-density genetic linkage maps of soybean for seed storability. In this regard, two recombinant inbred line (RIL) populations derived from Zhengyanghuangdou $\times$ Meng 8206 (ZM6) and Linhefenqingdou $\times$ Meng 8206 (LM6) crosses were evaluated for three seed-germination related traits viz., germination rate (GR), normal seedling length (SL) and normal seedling fresh weight (FW) under natural and artificial aging conditions to map QTLs for seed storability.

Results: A total of 34 QTLs, including 13 QTLs for GR, 11 QTLs for SL and 10 QTLs for FW, were identified on 11 chromosomes with the phenotypic variation ranged from 7.30 to $23.16 \%$ under both aging conditions. All these QTLs were novel, and 21 of these QTLs were clustered in five QTL-rich regions on four different chromosomes viz., Chr3, Chr5, Chr17 \&Chr18, among them the highest concentration of seven and six QTLs were found in "QTL hotspot A" (Chr17) and "QTL hotspot B" (Chr5), respectively. Furthermore, QTLs within all the five QTL clusters are linked to at least two studied traits, which is also supported by highly significant correlation between the three germination-related traits. QTLs for seed-germination related traits in "QTL hotspot B" were found in both RIL populations and aging conditions, and also QTLs underlying "QTL hotspot A" are identified in both RIL populations under artificial aging condition. These are the stable genomic regions governing the inheritance of seed storability in soybean, and will be the main focus for soybean breeders.

Conclusion: This study uncovers the genetic basis of seed storability in soybean. The newly identified QTLs provides valuable information, and will be main targets for fine mapping, candidate gene identification and markerassisted breeding. Hence, the present study is the first report for the comprehensive and detailed investigation of genetic architecture of seed storability in soybean.
\end{abstract}

Keywords: QTL, Seed storability, High-density linkage map, Seed aging, Soybean

\section{Background}

Soybean is one of the most important oil crop species for food, feed and of many industrial applications. This legume crop has originated in East Asia, and is now widely grown as primary oilseed crop with the United

\footnotetext{
* Correspondence: javid.akhter69@gmail.com; tjzhao@njau.edu.cn ${ }^{+} X i$ Zhang and Aiman Hina are contributed equally to this work. Soybean Research Institution, National Center for Soybean Improvement, Key Laboratory of Biology and Genetics and Breeding for Soybean, Ministry of Agriculture, State Key Laboratory of Crop Genetics and Germplasm. Enhancement, Nanjing Agricultural University, Nanjing 210095, China
}

States, Brazil, Argentina, India and China are the major soybean-growing countries $[1,2]$. In China, soybean production depends on maize-soybean intercropping, and the area under soybean crop has considerably increased in recent years $[3,4]$. However, it is interesting that despite of this, China is currently the major soybeanimporting country in the world for meeting the increasing requirement of plant protein, oil and food. Hence, it is an immediate need to improve soybean production for meeting the demand of its growing population.

(c) The Author(s). 2019 Open Access This article is distributed under the terms of the Creative Commons Attribution 4.0 International License (http://creativecommons.org/licenses/by/4.0/), which permits unrestricted use, distribution, and 
Seed germination is a most important stage in the life cycle of plant, and it determines the distribution of wild species as well as the increased yield and quality of cultivated crop species $[5,6]$. Generally, seed germination is completed following the emergence of the radicle [7]. Immediately after seed germination, another crucial development stage is seedling establishment in which transition occurs from heterotrophic to autotrophic state [8]. Therefore, for normal plant development both seed germination and seedling establishment are important. It is very important to mention that both these processes draw their energy from the seed stored in it [9]. However, after the seed is mature, it enters into the storage or dormancy phase. In crop species, as the time of storage for seeds increases, the irreversible process of declining seed vigor is initiated, called seed deterioration/aging [10]. Seed aging is an inevitable phenomenon in which the seeds lose their vigor and viability during the process of storage [11].

Seed storability is defined as the longevity of seeds after storage, and is important agronomic factor for the preservation of seed fitness after harvest [12]. Poor longevity causes loss of seed viability during storage, and negatively impacts seedling establishment and crop productivity $[13,14]$. This is major problem for soybean seeds, which lost their vigor and viability rapidly during storage, especially in high temperature and humid environment [15]. By considering the relative storability index, soybean is categorized in the least storable group [16]. Many previous studies have revealed that soybean seeds contain much higher oil and fatty acid contents compared to the cereal crop seeds, including wheat, rice and maize, which results shorter viability of soybean seed in storage [17-19]. During storage, seed respiration utilizes various biomolecules viz., glucose, oils and fatty acids, which significantly reduces seed longevity, and decreases the rate of seed germination and seedling establishment, even causing soybean seeds stored for long period incapable of germination [20, 21]. The germination ability of aged soybean seed decreases considerably with increasing storage time [22]. Moreover, seed longevity is vital for the preservation of soybean genetic resources through dry seeds [23]. High germination and seedling vigor (seedling fresh weight and length) after long-term storage in both normal and low temperature conditions reduce the risk of lower yields [24]. Climate characterized by high relative humidity and temperature (humid tropical and sub-tropical climate) are the most conducive environment for seed deterioration of soybean during storage, leading to poor germination and suboptimal plant stand [25]. It has particular significance in China where the climate is very hot and humid in most part of the year, especially in the north-eastern parts which is the major soybean growing region of China
[26]. Hence, development of soybean varieties that are resistant to adverse storage conditions is a most promising option to reduce loss of seed vigor and viability during storage. However, it requires the resistant genetic material, therefore soybean genotypes resistant to the adverse storage conditions must be identified. Then, genetic markers associated to seed storability should be identified to speed up breeding programmes by using marker-assisted breeding (MAB).

Quantitative trait loci (QTL) analysis is a powerful tool to decipher the molecular basis of complex traits. Variation in seed storability among soybean cultivars originating from different geographic regions have been reported [27]. Natural ageing and accelerated ageing are the two methods used in seed storability research [18, 28]. As seed storability under normal storage conditions takes years to complete, therefore artificially accelerated aging with elevated ambient temperature and relative humidity $(\mathrm{RH})$ was used to rapidly assess seed storability of Arabidopsis [29], rice [12, 18], lettuce [30], wheat [31], Brassica napus [32] and maize [13]. Four QTLs related to seed storability of soybean on chromosomes 2, 8, 12 and 16 were identified using a $F_{2}$ population of Birsa soya-1/ JS 71-05 [27]. Similarly, eight QTLs for seed storability were mapped on chromosome 1, 3, 4, 6, 8 and 9 of rice using doubled-haploid population that consist of 120 lines derived from the cross CJ06/TN1 [18]. Besides, ninety-six QTLs were detected for seed vigor-related traits under artificial aging condition on all wheat chromosomes except 2B, 4D, 6D, and 7D, explaining $2.9-19.4 \%$ of the phenotypic variance, using recombinant inbred line (RIL) population derived from $\mathrm{ZB} / \mathrm{CS}$ [31].

In soybean, no studies for the identification of QTLs under natural aging condition have been carried out. It is very important to determine whether same or different genetic factors determine the seed storability under two different aging conditions. Although, previous studies have shown that the aging mechanism of seed under high temperature and humidity conditions is consistent with the mechanism of aging under natural conditions, but the speed of deterioration is different, and the method of artificial aging seed can be used to study the physiological and biochemical changes of natural aging seeds [33, 34]. Under natural storage conditions, QTLs controlling storability were detected in diverse genetic backgrounds of different crop species. For example, Sasaki et al. [35] identified four QTLs associated to seed longevity in rice under natural aging condition using RIL ( $\mathrm{F}_{7}$ generation) population derived from a cross Milyang 23/Akihikari. Similarly, six QTLs linked to seed storability were identified on six chromosomes under normal aging condition in rice by using 182 backcross RILs derived from Koshihikari/Kasalath cross [36]. However, limited information is available for QTL analysis of seed 
storability under multiple treated conditions and diverse genetic backgrounds in soybean.

There are scarce reports related to the QTLs for soybean seed storability, and the physiological or molecular mechanisms underlying soybean seed storability are largely unclear. In the present study, the QTLs for three germination-related traits viz., GR, SL and FW under natural aging and artificial aging were detected using the two RIL population derived from a cross between the common male parent Meng 8206 with the two soybean lines viz., Zhengyanghuangdou and Linhefenqingdou. We identified the five QTL clusters/hot regions for seed storability, among which "QTL hotspot A" and "QTL hotspot B" are the major and stable genomic regions governing the inheritance of seed storability in soybean. Our results provide new insights into the genetic mechanism controlling seed storability in soybean. In addition, the QTLs reported in this study will be useful for marker-assisted breeding to achieve high seed storability.

\section{Results}

\section{Correlation analysis among traits}

Values of correlation coefficients among three germinationrelated traits based on data recorded under natural and artificial aging conditions for the LM6 and ZM6 RIL populations are presented in Table 1 . The results revealed that all the three traits used to access the seed storability of soybean show significantly high positive correlation $(P<0.01)$ under both aging conditions as well as in both RIL populations (Table 1). The treatment trait value was used for correlation analysis in the natural aging, whereas relative trait value was used in case of artificial aging. This highly significant positive correlation among the three germinationrelated traits under both aging treatments suggests that seed storability is most likely controlled by the same genetic factors under natural and artificial conditions.

Table 1 Pearson's correlation coefficients among three seed germination-related traits (GR, SL \& FW) based on agronomic data of LM6 and ZM6 RIL populations under natural and artificial aging conditions

\begin{tabular}{|c|c|c|c|c|c|}
\hline \multirow[t]{2}{*}{ Treatment } & \multirow[t]{2}{*}{ Trait } & \multicolumn{2}{|l|}{ LM6 } & \multicolumn{2}{|l|}{ ZM6 } \\
\hline & & $\mathrm{GR} / \mathrm{rGR}$ & $\mathrm{SL} / \mathrm{rSL}$ & $\mathrm{GR} / \mathrm{rGR}$ & $\mathrm{SL} / \mathrm{rSL}$ \\
\hline \multirow[t]{2}{*}{ Natural aging } & SL & $0.552^{b}$ & & $0.528^{b}$ & \\
\hline & FW & $0.742^{b}$ & $0.549^{b}$ & $0.754^{b}$ & $0.567^{\mathrm{b}}$ \\
\hline \multirow[t]{2}{*}{ Artificial aging } & rSL & $0.768^{b}$ & & $0.882^{b}$ & \\
\hline & rFW & $0.948^{\mathrm{b}}$ & $0.744^{b}$ & $0.884^{b}$ & $0.816^{\mathrm{b}}$ \\
\hline
\end{tabular}

In case of natural aging, the treatment trait value were used such as $G R$ (germination rate), $S L$ (seedling length) and $F W$ (fresh weight); Under artificial aging, relative treatment value were used such as $r G R$ (relative germination rate), $r S L$ (relative seedling length) and $r F W$ (relative fresh weight). ${ }^{a} \&^{b}$ represent significance at 5 and $1 \%$, respectively

\section{Phenotypes of RIL mapping populations}

Three parental accessions viz., Meng8206, Zhengyanghuangdou and Linhefenqingdou used for the construction of two RIL populations were evaluated for seed storability under artificial aging treatment by using three related traits such as GR, normal seedling rate (NSR) and FW. The Meng8206 revealed best performance for all the above three traits related to seed storability at different time intervals $(0 \mathrm{~d}, 1 \mathrm{~d}, 3 \mathrm{~d}, 4 \mathrm{~d}, 5 \mathrm{~d}, 6 \mathrm{~d}, 7 \mathrm{~d} \& 8 \mathrm{~d})$ of artificial aging treatment compared to two female parents Zhengyanghuangdou and Linhefenqingdou (Fig. 1). This indicates higher seed storability of Meng8206 relative to female parents (Fig. 1). Descriptive statistics, ANOVA ( $F$-value) and estimates of heritability showing distribution for all the three germination-related traits in both RIL populations under natural and artificial aging conditions are summarized in Table 2. The frequency distributions for the three traits viz., GR, SL and FW evaluated under natural and artificial aging for both RIL populations (LM6 \& ZM6) are given in Additional file 1: Figure S1. All three traits showed normal distribution under natural aging in both RIL population, whereas these three traits displayed various levels of skewedness under artificial aging (Additional file 1: Figure S1). In case of natural aging, control was not available and only treatment value of traits were used for descriptive statistics analysis, whereas control was used for artificial aging treatment, hence both treatment and relative value have been used for this analysis (Table 2). Under natural aging treatment, the average GR was 79.60 and $79.87 \%$ for LM6 and ZM6 populations, respectively. The phenotypic values for each trait exhibited wide range, with the $\mathrm{CV}(\%)$ ranging from $15.92 \%$ (SL) to $23.53 \%$ (FW) in LM6 population and $14.98 \%$ (SL) to $27.40 \%$ (FW) in ZM6 population. Estimates of heritability for the three traits varied from moderate $\left(20 \%<\mathrm{H}^{2}>50 \%\right)$ to high $(>$ $50 \%$; Table 2). A minimum of $42.30 \%$ heritability was reported for SD in ZM6 population and maximum of 74.01\% heritability was observed for FW in LM6 population. Furthermore, the $F$-value is highly significant for all the three traits in both RIL populations, indicating considerable phenotypic variation for these traits.

In the artificial accelerated aging conditions, the relative germination rate (rGR) of LM6 and ZM6 populations were 25.62 and $14.37 \%$, respectively. The relative phenotypic values for each trait revealed wide range, with the CV (\%) ranging from $57.91 \%$ (rSL) to $83.92 \%$ (rFW) in LM6 population and $108.25 \%$ (rSL) to $132.48 \%$ $(\mathrm{rFW})$ in ZM6 population. Estimates of heritability for the three traits were high ( $>69 \%$; Table 2$)$. A minimum of $73.58 \%$ heritability was observed for rSL in LM6 population and maximum of $89.13 \%$ heritability was observed for rGR in LM6 population. Furthermore, the $F$ value is highly significant for all the three traits in both 


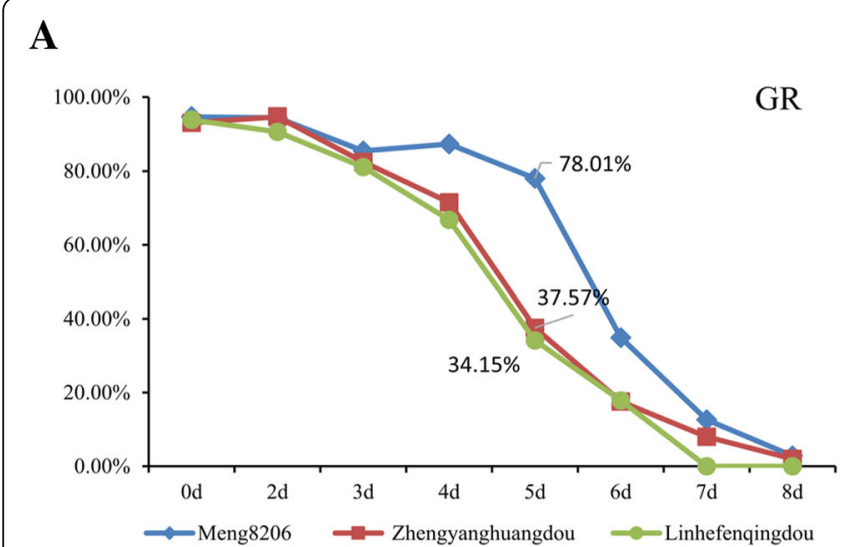

\section{B}

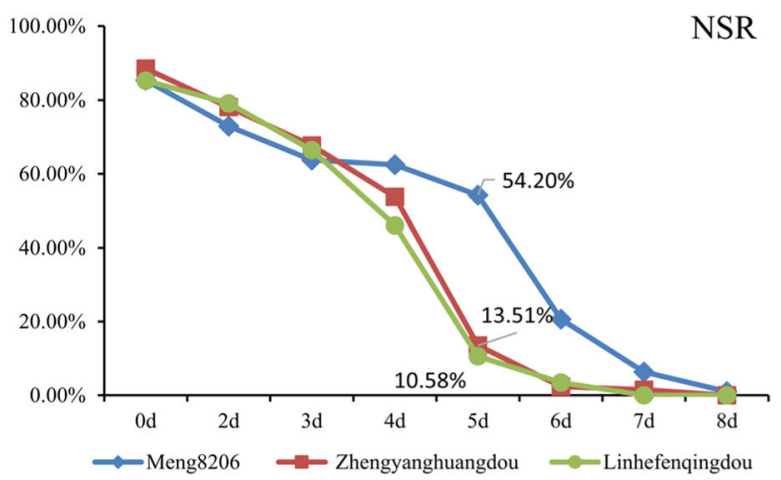

C

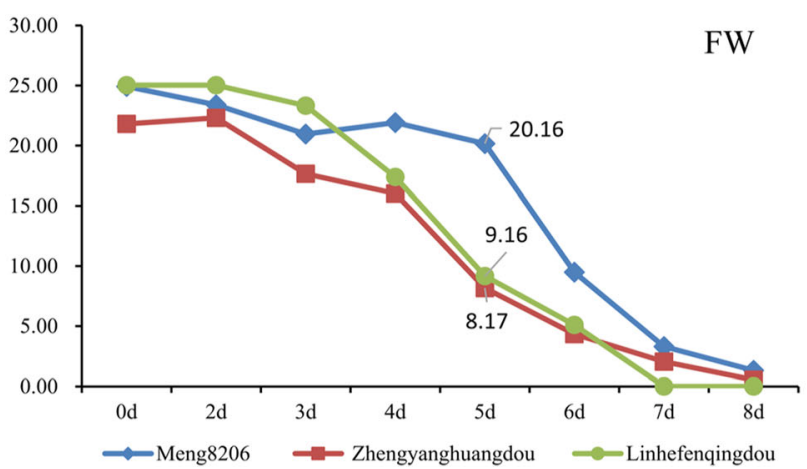

Fig. 1 Diagram showing the performance of three parents viz., Meng8206, Zhengyanghuangdou and Linhefenqingdou of RIL populations for three traits such as germination rate (GR), normal seedling rate (NSR) and normal seedling fresh weight (FW) that are used to evaluate seed storability of soybean under artificial aging treatment. (A) Germination rate/GR; (B) Normal seedling rate/NSR; (C) Normal seedling fresh weight

RIL populations, indicating considerable genetic variation for these traits under artificial aging condition.

Moreover, in almost all cases, the mean trait values (treatment value) in natural aging condition were higher than those in the respective artificial aging condition (Table 2). In summary, the extent of available variation and heritability for the three germination-related traits under both aging conditions were suitable for QTL analysis.

\section{QTL analysis for germination-related traits under natural aging condition}

Genome-wide analyses were performed using the highdensity genetic maps and phenotypic data of three germination-related traits (used to access seed storability) from RILs of the two populations (LM6 \& ZM6) under natural aging condition. High-density genetic map of the both LM6 and ZM6 populations consist of 20 linkage groups, and contains 2267 and 2600 bin markers, respectively. The total length of the LM6 and ZM6 maps was $2453.789 \mathrm{cM}$ and 2630.215 with average distance between the markers were $1.08 \mathrm{cM}$ and 1.01 cM, respectively (Additional file 2: Table S1 and S2). The average length of each linkage group was $122.67 \mathrm{cM}$ and $131.51 \mathrm{cM}$ for LM6 and ZM6 linkage maps with the mean marker density of each linkage group was 113 and 130, respectively (Additional file 2: Table S1 and S2). In total, 16 QTLs explaining 7.82-16.76\% phenotypic variation $\left(R^{2}\right)$ associated with three germination-related traits were detected in two RIL populations under natural aging condition (Table 3). For the LM6 population, eight QTLs associated with three germination-related traits including GR, SL and FW were identified on four chromosomes (Chr4, Chr5, Chr11 \& Chr17). A single QTL explained $8.97 \%(q F W-11-1)$ to $15.08 \%(q S L-17-2)$ of phenotypic variance. Among these QTLs, three are located on Chr5 (qGR-5-1, qGR-5-2 \& qFW-5-1) and the other three are present on Chr17 (qGR-17-1, qSL-17$1 \& q S L-17-2)$, and the remaining two viz., $q F W-4-1$ and $q F W-11-1$ are located on Chr4 and Chr11, respectively (Table 3). Out of these eight QTLs, seven are major with $R^{2}$ value $>10 \%$, and only $q F W-11-1$ is minor QTL with $R^{2}$ value $8.97 \%$. The most prominent QTL with the highest LOD score (5.07) was identified in a $60.91 \mathrm{cM}$ region, which we designated $q G R-5-2$, explained $15.05 \%$ of 
Table 2 Descriptive statistics (mean, SD, maximum and minimum value, CV\%), heritability and F-value of three seed germinationrelated traits (GR, SL \& FW) measured on LM6 and ZM6 RIL populations under natural and artificial aging treatments

\begin{tabular}{|c|c|c|c|c|c|c|c|c|}
\hline Aging treatment & Traits & Mean & SD & Minimum value & Maximum value & CV (\%) & Heritability(\%) & $F$-value \\
\hline \multirow[t]{3}{*}{ Natural-LM6 } & GR (\%) & 79.60 & 12.70 & 38.78 & 100.00 & 15.95 & 53.27 & $2.14^{* *}$ \\
\hline & $\mathrm{SL}(\mathrm{cm})$ & 16.00 & 2.55 & 8.38 & 21.00 & 15.92 & 53.32 & $2.14^{* *}$ \\
\hline & FW(g) & 26.64 & 6.27 & 13.16 & 44.86 & 23.53 & 74.01 & $3.85^{* *}$ \\
\hline \multirow[t]{3}{*}{ Natural-ZM6 } & GR (\%) & 79.87 & 12.26 & 43.04 & 100.00 & 15.35 & 56.76 & $2.31^{* *}$ \\
\hline & $\mathrm{SL}(\mathrm{cm})$ & 17.51 & 2.62 & 10.43 & 23.51 & 14.98 & 42.30 & $1.66^{* *}$ \\
\hline & FW (g) & 21.90 & 6.00 & 5.78 & 33.72 & 27.40 & 64.28 & $2.80^{* *}$ \\
\hline \multirow[t]{3}{*}{ Artificial-LM6 } & GR (\%) & 22.40 & 16.31 & 0.00 & 71.60 & 72.83 & 87.34 & $7.90^{* *}$ \\
\hline & $\mathrm{FW}(\mathrm{cm})$ & 4.40 & 2.16 & 0.00 & 10.09 & 49.19 & 76.10 & $4.18^{* *}$ \\
\hline & $S L(g)$ & 5.98 & 4.73 & 0.00 & 22.09 & 79.10 & 89.78 & $9.78^{* *}$ \\
\hline \multirow[t]{3}{*}{ Artificial-LM6 } & rGR (\%) & 25.62 & 19.24 & 0.00 & 76.20 & 75.09 & 89.13 & $9.20^{* *}$ \\
\hline & rSL (\%) & 23.45 & 13.58 & 0.00 & 60.09 & 57.91 & 73.58 & $3.78^{* *}$ \\
\hline & rFW (\%) & 16.83 & 14.12 & 0.00 & 66.47 & 83.92 & 88.96 & $9.06^{* *}$ \\
\hline \multirow[t]{3}{*}{ Artificial-ZM6 } & $\mathrm{GR}(\%)$ & 13.65 & 14.29 & 0.00 & 78.18 & 104.69 & 69.14 & $3.24^{* *}$ \\
\hline & $\mathrm{SL}(\mathrm{cm})$ & 2.50 & 2.24 & 0.00 & 12.36 & 89.58 & 75.49 & $4.08^{* *}$ \\
\hline & FW (g) & 2.55 & 3.02 & 0.00 & 16.87 & 118.57 & 75.83 & $4.14^{* *}$ \\
\hline \multirow[t]{3}{*}{ Artificial-ZM6 } & rGR (\%) & 14.37 & 16.26 & 0.00 & 90.70 & 113.17 & 83.80 & $6.17^{* *}$ \\
\hline & rSL (\%) & 11.42 & 12.37 & 0.00 & 89.66 & 108.25 & 75.10 & $4.02^{* *}$ \\
\hline & rFW (\%) & 7.87 & 10.43 & 0.00 & 63.93 & 132.48 & 74.63 & $3.94^{* *}$ \\
\hline
\end{tabular}

$S D$ (standard deviation); CV (coefficient of variation); GR (germination rate), SL (seedling length) and FW (fresh weight); $r G R$ (relative germination rate), $r S L$ (relative seedling length) and $r F W$ (relative fresh weight). Artificial aging includes both treatment and relative trait values, whereas natural aging includes only treatment trait value (no control was used in natural aging). ${ }^{*}{ }^{* *}$ represent significance at 5 and $1 \%$ probability levels, respectively

Table 3 QTLs identified for three seed-germination related traits (GR, SL \& FW) in LM6 and ZM6 RIL populations under natural aging treatment

\begin{tabular}{|c|c|c|c|c|c|c|c|c|}
\hline Aging treatment & Trait & QTL & Chromosome (Linkage group) & Position (cM) & Marker & LOD value & Additive effect & $R^{2}$ value (\%) \\
\hline \multirow[t]{8}{*}{ Natural-LM6 } & \multirow[t]{3}{*}{ GR } & $q G R-5-1$ & $5(\mathrm{~A} 1)$ & 52.31 & bin502-bin503 & 3.63 & -0.05 & 11.13 \\
\hline & & $q G R-5-2$ & $5(\mathrm{~A} 1)$ & 60.91 & bin512-bin513 & 5.07 & -0.05 & 15.05 \\
\hline & & $q G R-17-1$ & $17(\mathrm{D} 2)$ & 50.41 & bin1872-bin1873 & 3.49 & -0.06 & 12.98 \\
\hline & \multirow[t]{2}{*}{ SL } & qSL-17-1 & $17(\mathrm{D} 2)$ & 38.21 & bin1864-bin1865 & 4.77 & -1.04 & 14.53 \\
\hline & & qSL-17-2 & $17(\mathrm{D} 2)$ & 45.41 & bin1872-bin1873 & 4.44 & -1.04 & 15.08 \\
\hline & \multirow[t]{3}{*}{ FW } & $q F W-4-1$ & $4(\mathrm{C} 1)$ & 92.61 & bin426-bin427 & 3.70 & 2.18 & 10.80 \\
\hline & & $q F W-5-1$ & $5(\mathrm{~A} 1)$ & 60.91 & bin512-bin513 & 4.46 & -2.45 & 13.56 \\
\hline & & $q F W-11-1$ & $11(\mathrm{~B} 1)$ & 76.41 & bin1201-bin1202 & 3.00 & 2.03 & 8.97 \\
\hline \multirow[t]{8}{*}{ Natural-ZM6 } & \multirow[t]{3}{*}{ GR } & $q G R-5-3$ & $5(\mathrm{~A} 1)$ & 71.91 & bin571-bin572 & 6.64 & 0.06 & 16.76 \\
\hline & & $q G R-7-1$ & $7(\mathrm{M})$ & 114.81 & bin891-bin892 & 3.68 & 0.05 & 9.43 \\
\hline & & $q G R-15-1$ & $15(\mathrm{E})$ & 104.01 & bin1942-bin1943 & 3.78 & -0.05 & 9.13 \\
\hline & \multirow[t]{3}{*}{$S L$} & $9 S L-6-1$ & $6(C 2)$ & 82.61 & bin681-bin682 & 3.20 & -0.83 & 8.33 \\
\hline & & $9 S L-8-1$ & $8(A 2)$ & 70.51 & bin958-bin959 & 3.04 & -0.80 & 7.82 \\
\hline & & qSL-18-1 & $18(\mathrm{G})$ & 96.51 & bin2290-bin2290 & 3.19 & -0.81 & 8.16 \\
\hline & \multirow[t]{2}{*}{ FW } & $q F W-5-2$ & $5(\mathrm{~A} 1)$ & 71.91 & bin571-bin572 & 3.25 & 1.87 & 8.57 \\
\hline & & aFW-9-1 & $9(K)$ & 36.01 & bin1118-bin1119 & 5.43 & 2.44 & 14.89 \\
\hline
\end{tabular}

GR (germination rate), SL (seedling length) and FW (fresh weight); $\mathrm{R}^{2}=$ Coefficient of determination/phenotypic variance explained (PVE). In natural aging condition, control was not used, and we used treatment trait value for QTL analysis 
phenotypic variation and displayed a negative additive effect, mainly with the positive allele from the Meng 8206 . In addition, six out of eight QTLs showed negative additive effect with positive alleles from Meng 8206, only two QTLs ( $q F W-4-1$ and $q F W-11-1$ ) display positive additive effect with positive allele from Linhefenqingdou. The three QTLs detected on both Chr5 and Chr17 span approximately an interval of 13 and $17 \mathrm{cM}$, respectively on the respective chromosomes, indicating there are QTL clusters on Chr5 and Chr17. Interestingly, all the QTL within these clusters are major QTLs with $R^{2}>10 \%$ and LOD value $>3$, suggesting that $\mathrm{Chr} 5$ and $\mathrm{Chr} 17$ are most likely rich in genes governing seed storability in soybean.

In the case of ZM6 population, together eight QTLs were also identified for GR, SL and FW traits on seven chromosomes (Chr5, Chr6, Chr7, Chr8, Chr9, Chr15 \& Chr18) explaining 7.82 to $16.76 \%$ of the phenotypic variance (PV) under natural aging condition (Table 3). Of the eight QTLs, six are minor with $R^{2}$ value $<10 \%$ and only two QTLs viz., $q G R-5-3$ and $q F W-9-1$ are major $\left(R^{2}\right.$ value $>10 \%)$. The QTL with the highest LOD score (6.64) was identified in a $71.91 \mathrm{cM}$ region, and are designated as $q G R-5-3$, explaining $16.76 \%$ of phenotypic variation, with the positive allele from the Zhengyanghuangdou (Table 3). Four QTLs (qGR-15-1, $q S L-6-1, q S L-8-1$ and $q S L-18-1)$ showed negative additive effect with positive allele from Meng 8206, and the remaining three QTLs viz., $q G R-7-1, q F W-5-2$ and $q F W-$ 9-1 displayed positive additive effects with positive alleles from Zhengyanghuangdou. The two major QTLs ( $q$ GR-5-3\&qFW-9-1) identified in ZM6 population are located on Chr5 and Chr9, respectively, and in addition prominent QTLs identified in both LM6 (qGR-5-2) and ZM6 (qGR-5-3) populations are also located on Chr5, hence provides valid evidence for the important role of Chr5 in seed storability under natural aging condition.

\section{QTL analysis for germination-related traits under artificial aging condition}

Under artificial aging condition, the relative trait value of three germination-related traits viz., rGR, rSL and rFW have been used for the mapping of QTLs for seed storability (Table 4). In LM6 population, together 10 QTLs were identified for rGR, rSL and rFW traits on five chromosomes viz., Chr3, Chr5, Chr6, Chr9 \& Chr17, explaining 8.14 to $23.16 \%$ of the phenotypic variance (PV) under artificial aging condition. The four, three and three QTLs have been identified for rGR, rSL and $\mathrm{rFW}$ traits, respectively. Among these QTLs, four are located on Chr17 (qrGR-17-1, qrGR-17-2, qrFW-171 and $q r F W-17-2)$ and three are present on Chr3 ( $q r G R$ 3-1, qrGR-3-2 and qrFW-3-1), and the remaining three viz., qrSL-5-1, qrSL-6-1 and qrSL-9-1 are located on Chr5, Chr6 and Chr9, respectively (Table 4). Of the 10

Table 4 QTLs identified for three seed-germination related traits (GR, SL \& FW) in LM6 and ZM6 RIL populations under artificial aging treatment

\begin{tabular}{|c|c|c|c|c|c|c|c|c|}
\hline Aging treatment & Traits & QTL & Chromosome (Linkage group) & Position(cM) & Marker & LOD value & Additive effect & $R^{2}$ value(\%) \\
\hline \multirow[t]{10}{*}{ Artificial-LM6 } & \multirow[t]{4}{*}{$r G R$} & $\operatorname{arGR-3-1}$ & $3(N)$ & 1.01 & bin228-bin229 & 3.37 & 0.06 & 8.94 \\
\hline & & $\operatorname{arGR-3-2}$ & $3(N)$ & 81.01 & bin322-bin323 & 3.43 & -0.05 & 8.14 \\
\hline & & $\operatorname{arGR-17-1}$ & $17(\mathrm{D} 2)$ & 113.31 & bin1924-bin1925 & 7.05 & 0.09 & 19.11 \\
\hline & & $\operatorname{arGR-17-2}$ & $17(\mathrm{D} 2)$ & 123.01 & bin1930-bin1931 & 8.65 & 0.09 & 22.64 \\
\hline & \multirow[t]{3}{*}{$r S L$} & $\operatorname{arSL}-5-1$ & $5(\mathrm{~A} 1)$ & 55.51 & bin505-bin506 & 4.09 & 0.01 & 11.78 \\
\hline & & arSL-6-1 & $6(C 2)$ & 62.11 & bin613-bin614 & 4.06 & -0.01 & 11.75 \\
\hline & & $\operatorname{arSL}-9-1$ & $9(K)$ & 77.51 & bin1057-bin1058 & 4.12 & 0.02 & 11.92 \\
\hline & \multirow[t]{3}{*}{ rFW } & $\operatorname{arFW}-3-1$ & $3(\mathrm{~N})$ & 3.31 & bin231-bin232 & 3.50 & 0.04 & 8.51 \\
\hline & & qrFW-17-1 & 17 (D2) & 116.51 & bin1925-bin1926 & 6.41 & 0.07 & 19.05 \\
\hline & & arFW-17-2 & 17 (D2) & 123.01 & bin1930-bin1931 & 8.33 & 0.07 & 23.16 \\
\hline \multirow[t]{8}{*}{ Artificial-ZM6 } & \multirow[t]{3}{*}{$r G R$} & $\operatorname{arGR-10-1}$ & $10(\mathrm{O})$ & 91.21 & bin1313-bin1314 & 3.73 & 0.05 & 8.69 \\
\hline & & $\operatorname{arGR-17-3}$ & 17 (D2) & 130.21 & bin2176-bin2177 & 4.26 & -0.05 & 10.56 \\
\hline & & $\operatorname{arGR-18-1}$ & $18(\mathrm{G})$ & 47.91 & bin2226-bin2227 & 6.61 & 0.07 & 16.03 \\
\hline & \multirow[t]{3}{*}{$r S L$} & arSL-17-1 & 17 (D2) & 128.21 & bin2176-bin2177 & 3.09 & -0.03 & 7.38 \\
\hline & & $\operatorname{arSL}-18-1$ & $18(\mathrm{G})$ & 35.21 & bin2218-bin2219 & 3.05 & 0.03 & 7.38 \\
\hline & & arSL-18-2 & $18(\mathrm{G})$ & 50.01 & bin2228-bin2229 & 3.01 & 0.03 & 7.30 \\
\hline & \multirow[t]{2}{*}{ rFW } & arFW-11-1 & $11(\mathrm{~B} 1)$ & 3.51 & bin1356-bin1357 & 3.25 & -0.04 & 8.50 \\
\hline & & arFW-17-3 & 17 (D2) & 129.21 & bin2176-bin2177 & 4.26 & -0.04 & 11.44 \\
\hline
\end{tabular}


QTLs, seven are major with $R^{2}$ value $>10 \%$ and only three QTLs viz., $q r G R-3-1, q r G R-3-2$ and $q r F W-3-1$ have $R^{2}$ value $<10 \%$ (minor). Most prominent QTL ( $q r F W-17-2$ ) was identified in a $123.01 \mathrm{cM}$ region having LOD score of 8.33 and $R^{2}=23.16 \%$, with the positive allele derived from the Linhefenqingdou. Only two QTLs viz., $q r G R-3-2$ and qrSL-6-1 revealed negative additive effect with positive allele from Meng 8206, and the remaining all eight QTLs displayed positive additive effects with positive alleles from Linhefenqingdou. The four QTLs were detected in approximately $12 \mathrm{cM}$ interval on $\mathrm{Chr} 17$ indicating there are QTL clusters on Chr17. Interestingly, all the QTLs within this clusters are major QTLs with $R^{2}>10 \%$ and LOD value $>6$, this further corroborate that Chr17 is most likely rich in key genes controlling seed storability in soybean.

For the ZM6 population, eight QTLs were identified for rGR, rSL and rFW traits on four chromosomes (Chr10, Chr11, Chr17 \& Chr18) under artificial aging (Table 4). A single QTL explained 7.30\% ( $q r S L-18-2$ )-16.03\% ( $q r G R$ 18-1) of phenotypic variance. Out of these eight QTLs, five are minor with $R^{2}$ value $<10 \%$, and the remaining three viz., $q r G R-17-3$, $q r G R-18-1$ and $q r F W-17-1$ are major QTLs with $R^{2}$ value $>10$. The $q G R-18-1$ was identified as the most prominent QTL with the highest LOD score (6.61), explained $16.03 \%$ of phenotypic variation and displayed a positive additive effect, with the positive allele from the Zhengyanghuangdou. In addition, four QTLs viz., $q r G R-17-3, q r S L-17-1, q r F W-11-1$ and $q r F W-17-3$ showed negative additive effect with positive alleles from Meng 8206, and the remaining three QTLs display positive additive effect with positive allele from Zhengyanghuangdou (Table 4). The three QTLs were detected in approximately $3 \mathrm{cM}$ interval on $\mathrm{Chr} 17$ indicating there are QTL clusters on Chr17. Interestingly, two out of three QTLs within this cluster are major QTLs with $R^{2}>10 \%$ and LOD value $>4$. Hence, it is confirmed from both aging conditions and RIL populations, that Chr17 plays important role in governing inheritance of seed storability in soybean (Tables 3 \& 4).

\section{"QTL hotspots" and stable genomic regions for seed storability}

QTL cluster/hotspots is defined as a densely populated QTL region of the chromosome that contains multiple QTLs associated with various traits. In this study, we found five QTL clusters in four different chromosomes viz., Chr3, Chr5, Chr17 \&Chr18, and were named as Cluster-03, Cluster-05, Cluster-17.1, Cluster-17.2 and Cluster-18, respectively (Table 5). The highest concentration of QTLs for seed storability was identified in Cluster-17.2 of Chr17, and is designated as "QTL hotspot A" spanning physical length of $1.4 \mathrm{Mb}$ (Fig. 2). This QTL hotspot harbors seven QTLs (six major and one minor) viz., qrGR-17-1, qrGR-17-2, qrFW-17-1, qrFW-
17-2, qrGR-17-3, qrSL-17-1 and $q r F W-17-3$ associated to all three studied germination-related traits (Table 5). All the QTLs underlying "QTL hotspot A" are major QTLs $\left(\mathrm{R}^{2}>10 \%\right)$ expect qrSL-17-1, and explained 7.38$23.16 \%$ of phenotypic variation (Table 5). Another sets of QTL rich region was found in Cluster-05 on Chr5, and is designated as "QTL hotspot B" with length of 4.0 $\mathrm{Mb}$. It harbors six QTLs for all three germinationrelated traits that includes $q G R-5-1, q G R-5-2, q F W-5-1$, $q G R-5-3, q F W-5-2$ and $q r S L-5-1$. Out of these six QTLs, five are major $\left(R^{2}>10 \%\right)$ with only $q F W-5-2$ as minor QTL $\left(R^{2}<10 \%\right)$, and are explaining $8.57-16.76 \%$ of phenotypic variation (Table 5). The Cluster-3 contain two QTLs for two traits viz. rGR and rFW, explaining phenotypic variation of $8.51-8.94 \%$, whereas Cluster17.1 and Cluster-18 contain three QTLs each, explaining phenotypic variation of $12.98-15.08 \%$ and $7.30-16.03 \%$, respectively (Table 5). Furthermore, the QTLs within "QTL hotspot B" have been identified in both RIL populations as well as aging conditions, and in addition QTLs underlying "QTL hotspot A" have been identified in both RIL populations under artificial aging condition (Fig. 2, Table 5). Hence, these are the stable genomic regions governing the inheritance of seed storability in soybean.

All the model genes within the physical intervals of "QTL hotspot A" and "QTL hotspot B", and their gene annotations were downloaded from the Phytozome (https://phytozome.jgi.doe.gov) and Soybase (http:// www.soybase.org) databases. A total of 159 and 455 gene models were found in the "QTL hotspot A" and "QTL hotspot B" respectively. After screening 19 genes showed relationship with seed development, seed germination, seed dormancy, seed coat formation, fatty acid/lipid metabolic process and seed storage (Additional file 2: Table S3). Hence, based on their function we considered them as a possible candidate for seed storability. However, it needs further validation to prove their actual role in soybean seed storability.

\section{Discussion}

Poor storability results in considerable production and economic losses due to the impossibility of carry-over of seed lots, which have lost their vigor and viability, and are no longer marketable. Soybean seeds decline in quality very faster relative to the seeds of other crops [37]. It is a major problem for soybean production in the tropics and subtropics, where rapid loss of seed germination capacity occurs during storage under ambient storage conditions [38]. Moreover, in majority of countries especially developing and under-developed, most farmers have poor seed processing and storage facilities, resulting the viability of seed to lose faster. Storability is an important agronomic trait as far as crop production and germplasm conservation in gene 
Table 5 Five QTL hotspots/clusters detected in LM6 and ZM6 RIL population under natural and artificial conditions

\begin{tabular}{|c|c|c|c|c|c|c|}
\hline QTL cluster name & Chr_Bin range & Physical range (bp) & $\begin{array}{l}\text { QTL } \\
\text { Name }\end{array}$ & LOD & $\begin{array}{l}\text { Additive } \\
\text { effect }\end{array}$ & $\begin{array}{l}R^{2} \\
\text { (\%) }\end{array}$ \\
\hline \multirow[t]{2}{*}{ Cluster-03 } & \multirow[t]{2}{*}{ Chr03_bin228-bin232 (LM6) } & \multirow[t]{2}{*}{$00000001-00533669$} & $\operatorname{qrGR-3-1}$ & 3.37 & 0.06 & 8.94 \\
\hline & & & arFW-3-1 & 3.5 & 0.04 & 8.51 \\
\hline \multirow[t]{6}{*}{ Cluster-05/ QTL hotspot B } & \multirow[t]{6}{*}{ Chr05_bin502-bin513 (LM6) Chr05_bin571-bin572 (ZM6) } & \multirow[t]{6}{*}{$31,127,720-35,178,169$} & $q G R-5-1$ & 3.63 & -0.05 & 11.13 \\
\hline & & & $q G R-5-2$ & 5.07 & -0.05 & 15.05 \\
\hline & & & $q F W-5-1$ & 4.46 & -2.45 & 13.56 \\
\hline & & & $q G R-5-3$ & 6.64 & 0.06 & 16.76 \\
\hline & & & $q F W-5-2$ & 3.25 & 1.87 & 8.57 \\
\hline & & & $\operatorname{arSL}-5-1$ & 4.09 & 0.01 & 11.78 \\
\hline \multirow[t]{3}{*}{ Cluster-17.1 } & \multirow[t]{3}{*}{ Chr17_bin1864-bin1873 (LM6) } & \multirow[t]{3}{*}{$77,540,160-10,193,909$} & $q G R-17-1$ & 3.49 & -0.06 & 12.98 \\
\hline & & & $q S L-17-1$ & 4.77 & -1.04 & 14.53 \\
\hline & & & $q S L-17-2$ & 4.44 & -1.04 & 15.08 \\
\hline \multirow[t]{7}{*}{$\begin{array}{l}\text { Cluster-17.2/ QTL hotspot } \\
\text { A }\end{array}$} & \multirow[t]{7}{*}{$\begin{array}{l}\text { Chr17_bin1924-bin1931 (LM6) Chr17_bin2176-bin2177 } \\
\text { (ZM6) }\end{array}$} & \multirow[t]{7}{*}{$39,676,735-41,073,260$} & $\begin{array}{l}\operatorname{arGR-17-} \\
1\end{array}$ & 7.05 & 0.09 & 19.11 \\
\hline & & & $\operatorname{arGR-17-2}$ & 8.65 & 0.09 & 22.64 \\
\hline & & & $\begin{array}{l}\text { qrFW-17- } \\
1\end{array}$ & 6.41 & 0.07 & 19.05 \\
\hline & & & $\begin{array}{l}\text { qrFW-17- } \\
2\end{array}$ & 8.33 & 0.07 & 23.16 \\
\hline & & & $\operatorname{arGR-17-3}$ & 4.26 & -0.05 & 10.56 \\
\hline & & & arSL-17-1 & 3.09 & -0.03 & 7.38 \\
\hline & & & $\begin{array}{l}q r F W-17- \\
2\end{array}$ & 4.26 & -0.04 & 11.44 \\
\hline \multirow[t]{3}{*}{ Cluster-18 } & \multirow[t]{3}{*}{ Chr18_bin2218-bin2229 (ZM6) } & \multirow[t]{3}{*}{ 05407986-07447039 } & $\begin{array}{l}\operatorname{qrGR-18-} \\
1\end{array}$ & 6.61 & 0.07 & 16.03 \\
\hline & & & arSL-18-1 & 3.05 & 0.03 & 7.38 \\
\hline & & & $\operatorname{arSL}-18-2$ & 3.01 & 0.03 & 7.30 \\
\hline
\end{tabular}

banks is concerned $[24,39,40]$. Poor storability leads to unexpected losses in seed viability during storage and negatively impacts seedling establishment, crop production and yield. Hence, improving seed storability is important to increase overall crop production as well as play key role to maintain the global food security [15]. It is a complex quantitative trait, and is considerable influenced by growing environments. Despite the substantial research on storability, its mechanism is not clear and breeders have not applied currently available information. However, to breed for storability resistance, a full understanding of the genetic basis of resistance is indispensable. In this study, three different germination-related parameters were used for evaluating seed storability resistance under two different aging treatments (natural and artificial), and each trait revealed moderate to high broad-sense heritability. This indicates that storability resistance is environmentally stable in our study and mainly controlled by genetic factors. The high correlation coefficients of germination-related parameters under both natural and artificial aging conditions supported this result. Particularly, the highly significant correlation coefficient of GR with FW and SL implies that high GR is correlated with high FW and SL.

QTL mapping has been commonly used for the QTL/ gene identification in crop plants, and is an efficient approach to analyze quantitative traits. The quality of genetic maps has a great influence on the accuracy of QTL detection, and therefore increasing marker density can increase the resolution of genetic maps for a given mapping population $[41,42]$. Hence, it is prerequisite to prepare high-density linkage maps and thereby improve the efficiency and accuracy of linkage mapping and MAS. In this study, we used two high-density genetic maps of the LM6 and ZM6 populations contains 2267 and 2600 bin markers, respectively. The markers in both linkage maps were integrated to all the 20 LGs, and the average distance between adjacent markers was only $1.08 \mathrm{cM}$ and $1.01 \mathrm{cM}$ in case of LM6 and ZM6, respectively. These high-density genetic maps could ensure that a molecular marker and QTL were tightly linked, and provided a good foundation for analyzing quantitative traits.

Soybean seeds in storage or gene bank preservation of natural conditions gradually lose their germination 

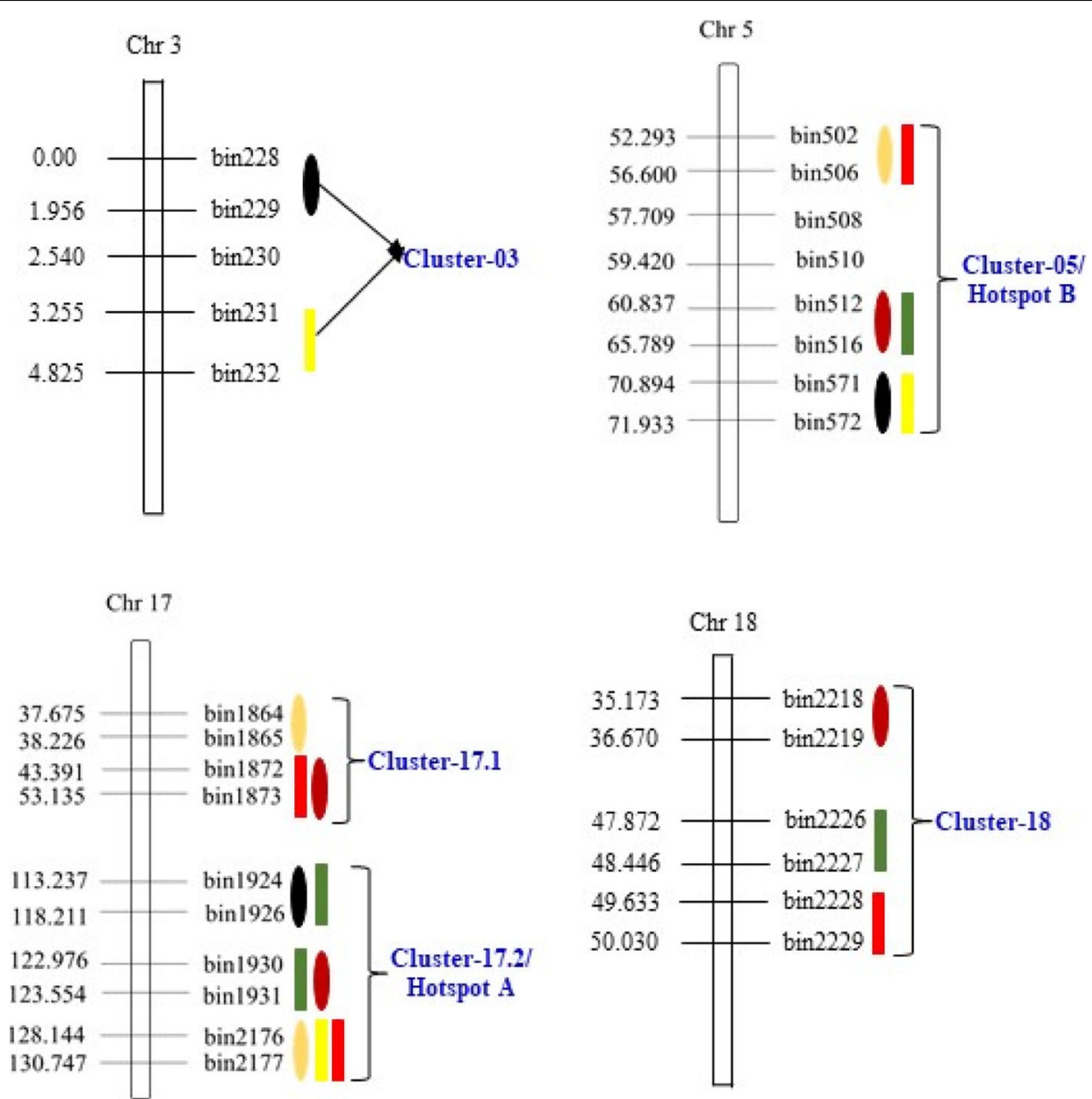

Fig. 2 Diagram showing the location of five QTL clusters/hot regions (cluster-03, cluster-05, cluster-17.1, cluster-17.2 and cluster-18) on four different chromosomes viz., Chr3, Chr5, Chr17 and Chr18 identified in LM6 and ZM6 RIL populations under natural and artificial aging conditions

ability. Natural aging lasts long time usually more than one year, and is difficult to apply for germplasm screening. Instead, artificial aging uses high temperature and humidity to model and speed the natural aging, and has been widely used in seed processing research [30, 43, 44]. However, only limited QTL studies have been carried out for seed longevity in soybean that have identified few QTLs associated with seed longevity and seedling vigor [27]. These QTLs were located on chromosomes 2, 8, $12 \& 16$. Moreover, most of the research on longevity was based on accelerated ageing [45]. However, results from natural and accelerated ageing indicate that there may be genetic differences in the results from the two systems [46]. We therefore used both natural and artificial aging conditions to elucidate whether or not the artificial aging mimic with natural aging completely. In this study, $q G R-5-1$ and $q r S L-5-1$ have been reported on Chr5 of LM6 population between the same bin502-bin506 marker interval under both natural and artificial aging treatment, respectively. The rest of the QTLs identified for seed storability under natural aging condition do not fall in a common marker-interval of the QTLs identified in artificial aging condition. This suggests that artificial aging treatments do not completely mimic deterioration process in conventional storage conditions. Some previous studies reported different deterioration mechanisms might be involved in natural and artificial accelerated storage [30]. Conversely, Likhatchev et al. [47] revealed that physiological changes in seeds were same under both conventional and artificial aging conditions. Similarly, by comparing the biochemical behavior of seeds under natural and artificial aging, it was suggested that similar molecular events occurs at both aging conditions, and artificial aging mimics the natural seed aging as was indicated by germination behavior [48]. The identification of common QTL ( $q G R$ 5-1 and qrSL-5-1) between the same marker interval under both aging condition in this study seems to support the latter conclusion. However, except $q G R-5-1$ and qrSL-5-1, the remaining QTLs identified in artificial aging treatment are not located at same marker interval of QTLs reported in natural aging, hence indicating that 
artificial aging does not completely mimic deterioration process in conventional storage conditions.

In the present study, a total of 16 and 18 QTLs were identified for seed storability under natural and artificial aging conditions, respectively. The nine ( $q G R-5-1, q G R-5-2, q G R-$ 17-1, qSL-17-1, qSL-17-2, qFW-4-1, qFW-5-1, qGR-5-3\& qFW-9-1) and ten (qrGR-17-1, qrGR-17-2, qrSL-5-1, qrSL-61, qrSL-9-1, qrFW-17-1, qrFW-17-2, qrGR-17-3, qrGR-18-1 \& qrFW-17-3) QTLs could be considered as the major QTLs for seed storability under natural and artificial aging condition, respectively, because of their larger LOD values (>3.5) and explained more of the PV(>10\%). Because some QTLs associated with seed storability/longevity have been previously reported, it is very important to identify novel QTLs associated with seed storability. Based on the QTLs listed in SoyBase (www.soybase.org), all the QTLs identified in this study are novel. Previously, the QTLs for seed longevity have been identified on four chromosomes viz., 2, 8, 12 \& 18 [27]. But in the present study the QTLs were identified on different chromosomes viz., [3-9, 11, 15, 17, 18], although one QTL $(q S L-8-1)$ has been identified on Chromosome 8 but that lies at considerable distance from the one identified previously (seed viability $1-1$ ) associated with Satt538 marker [27]. Moreover, all the seed longevity QTLs identified earlier were minor explaining less than $7.7 \%$ phenotypic variation $\left(R^{2}<0.075\right)$, and these QTLs have not been further characterized, validated as well as used in marker-assisted breeding for the improvement of seed storability in soybean. One of the reason will be the use of lowdensity linkage map based on low-throughput markers (SSR) in these studies, which does not provide the required information (i.e., number and resolution of QTLs/genes) as needed for marker-assisted breeding. Based on the highdensity genetic map, the confidence interval for most of the QTLs was less than $5 \mathrm{cM}$, and each QTL had two or more closely linked markers (within $0-5 \mathrm{cM}$ ). These loci are favorable for the MAS of QTLs by soybean breeding programs. Therefore, there was considerable lack of information about the genetic architecture of seed storability in soybean. Hence, the present study provides detailed understanding about QTLs/genes governing the inheritance of seed storability in soybean, and added information to the growing knowledge on the genetic control of seed storability.

Co-localization of QTL on chromosomes were detected for three germination-related traits determining the degree of seed storability in this study. QTL colocalization on chromosomes, referred to as "QTL cluster/hotspots", have been previously reported in soybean $[49,50]$. In the present research, a few genomic regions containing QTL clusters were examined, and five QTL clusters were found on four chromosomes viz.,3, 5, 17 and 18 (Fig. 2). These QTL clusters affected two or more different seed germination-related traits. The highest number of seven and six QTLs were observed on "QTL hotspot
A" and "QTL hotspot B", respectively harboring QTLs for all the three seed-germination related traits viz., GR, FW and SL (Fig. 2, Table 5). The other three clusters viz., Cluster-3, Cluster-17.1 and Cluster-18 contain two, three and three QTLs, respectively for at least two germinationrelated traits (Table 5). These QTLs clusters have not been published and add to the growing knowledge on the genetic control of these traits. The phenomenon of QTL clustering might represent the linkage of genes and QTL or result from pleiotropic effects of a single QTL in the same genomic region [49]. This co-localization of QTLs for three different germination-related traits was in accordance with the fact that all of them were highly significantly correlated with each other (Table 1). These QTL hotspot regions revealed that the linkage/pleiotropy QTLs will facilitate the improvement of seed storability. Previously, some of the QTLs for other traits have been also identified in the same region of "QTL hotspot A" on chromosome 17, that are related to oil content and fatty acid composition of soybean seed [51], days to flowering and maturity [52]. Similarly, earlier studies have also reported QTLs for seed oil, seed protein, flowering, seed set, shoot Fe \& Mg content and ureide content in the "QTL hotspot B" region on Chr5 [52-56]. The defective seed maturation leads to rapid loss of viability upon storage as has been shown for leafy cotyledon1 (lec1) and abscisic acid intensitive3 (abi3) mutants [57-59]. Seed maturity, viability and storability are correlated with each other [60]. The oil content and fatty acid composition plays an essential role in the viability of soybean seed during storage conditions. Seeds rich in lipids have poor longevity due to their specific chemical composition [61]. For example, soybean seed storage demands special attention due to high oil content, otherwise, processes may occur that lead to loss of germination ability and seed viability [61]. The development of rancidity has been recognized as the predominant cause of oil deterioration and reduction during storage [62]. This suggesting the potential probability of common genic factors for these traits, and also showing the necessity to promote further study for these regions. These QTL clusters have provided some valuable information to define genome regions with different traits. Based on the comprehensive analysis of clusters in this study, breeding programs targeting increase of seed storability with superior oil quality can focus on hotspot clustering areas and select around the region. Lastly, existence of QTL clusters/hotspots has provided proof that genes related to some crop traits are more densely concentrated in certain genomic regions of crop genomes than others $[63,64]$.

\section{Conclusion}

In conclusion, the present study is the first detailed and comprehensive investigation of QTLs for seed storability in soybean, in which we used high-density linkage maps 
of two RIL populations (LM6 and ZM6) for the discovery of storability QTLs. We identified 34 QTLs for three seed germination-related traits (used to access seed storability), out of which 19 are major QTLs with $R^{2}>10 \%$ and LOD $>3$. All the identified QTLs are novel, and has not been previously reported in soybean. Furthermore, 21 identified QTLs are clustered to five QTL clusters, among which "QTL hotspot A" and "QTL hotspot B" are the major and stable genomic regions governing the inheritance of seed storability in soybean. These regions could be the main focus of soybean breeders for fine mapping, candidate gene identification as well as marker-assisted selection of soybean genotypes with superior seed storability. Lastly, the improvement of seed storability in soybean will play considerable role in increasing overall production and yield, as well as avoid losses that results due to poor seed storability. Hence, seed storability has great importance in maintaining sustainable crop production as well as global food security.

\section{Methods}

\section{Plant materials}

In the present study, we used two sets of recombinant inbred line populations (RILs) developed from the Zhengyanghuangdou $\times$ Meng 8206 (ZM6) and Linhefenqingdou $\times$ Meng 8206 (LM6) crosses that consist of 126 and 104 lines, respectively. The Meng8206 parent (male) has good seed longevity, whereas Zhengyanghuangdou and Linhefenqingdou (female parents) have low seed longevity (Fig. 1). All the three parental accessions viz., Meng8206, Zhengyanghuangdou and Linhefenqingdou have been received from Soybean Germplasm Gene Bank at National Center for Soybean Improvement (Ministry of Agriculture), Nanjing Agricultural University, Nanjing, China, that are deposited there with Accession ID of N21257, N05082 and N06141, respectively. The average flowering/maturity time for Meng8206, Zhengyanghuangdou and Linhefenqingdou were 39.3/ $105,42.5 / 108$ and 49.9/115, respectively. Parental accessions and RIL populations were both planted in a randomized complete block design with three replications in the field at Jiangpu agricultural experiment station of Nanjing Agricultural University in the growing seasons of 2011 and 2014. The harvested seeds of both the populations were sundried until about $10 \%$ seed moisture, and then were used for evaluation of seed storability.

\section{Natural and artificial aging treatment Natural aging}

The seeds from both the RIL population planted in 2011 growing season were harvested in November 2011, and stored in the Seed Storage Room of National Soybean Improvement Center, Nanjing Agricultural University till July 2015. During this storage period the temperature was maintained at $20^{\circ} \mathrm{C}$ in the months of April-October but at room temperature in the remaining months i.e., November-March, with no control of humidity (40$70 \%)$. In July 2015 , seeds were removed from storage room for storability test [65].

\section{Artificial accelerated aging}

The artificial aging (AA) experiment was performed to determine the optimal aging conditions and duration [66]. Accelerated aging method of Singh and Ram [25], who kept seeds at $40{ }^{\circ} \mathrm{C}$ and $100 \% \mathrm{RH}$ (relative humidity) for $96 \mathrm{~h}$, was modified in an attempt to ensure clearcut differences between seeds of superior and poor storability. The $100 \%$ RH required for the AA test method as specified in the International Seed Inspection Code (ISIC) is difficult to achieve, and the seed was extremely sensitive at $100 \% \mathrm{RH}$. Fresh seed samples harvested in 2014 growing season of both RIL populations were enclosed in small nylon bags that are kept orderly in the aging box for 5 days under the artificial accelerated aging conditions of $45^{\circ} \mathrm{C} \pm 1$ and $95 \pm 1 \% \mathrm{RH}$. Seeds were subjected to standard germination tests randomly. The seed aging box was provided by Shanghai Qi Xin Scientific Instrument Co., Ltd., model LH-150S [65].

\section{Evaluation of seed storability}

In accordance to GB / T3543.4-1995 "Rules for agricultural seed testing procedure", the standard technical requirements for soybean germination was applied (https://www.chinesestandard.net/PDF/English.aspx/ GBT3543.4-1995). Fifty seeds with intact seed coat of each line exposed to either natural or artificial ageing conditions in two replicates were used for storability test. For germination test, the seeds were initially disinfected with $70 \%$ ethanol solution, then washed three times with sterile water and dried with a paper roll method [67], and dipped in a turnover box containing distilled water to a height of about $3 \mathrm{~cm}$, under the conditions of room temperature $\left(25^{\circ} \mathrm{C}\right)$ for 5 days to ensure normal germination.

For the evaluation of seed storability, the following three parameters related to seed germination and vigor were used viz., germination rate (GR; Number of germinated seeds/Total number of seeds $\times 100$ ), normal seedling length (SL) and normal seedling fresh weight (FW). In case of artificial aging, the control was also used that does not experience any aging treatment, hence the relative trait value were used for analysis such as relative germination rate (rGR), relative normal seedling length $(\mathrm{rSL})$ and relative normal seedling fresh weight $(\mathrm{rFW})$. The relative value of these three traits were calculated by the formula as Trait Value under Aging Treatment/ Trait Value of control $\times 100(\%)$. However, in case of 
natural aging no control was available, therefore we used treatment trait value for analysis [65].

\section{SNP genotyping and bin map construction}

Map construction begins with the extraction of genomic DNA from the young leaves of two RIL populations following the protocol of Zhang et al. (2004) [68]. This genomic DNA was digested using Taq I to construct genomic DNA library following Baird et al. [69]. DNA fragments between 400 and 700 bp were selected as well as sequenced using the Illumina HiSeq 2000 standard protocol for MSG (multiplexed shotgun genotyping), and 90-mer paired-end reads were generated [70]. SOAP2 software was used for aligning the sequenced reads to the Williams 82 reference genome [71]. SNP calling and genotyping were conducted using Real SFS software [72], based on the Bayesian estimation. Subsequently, using a three-standard filter, $50<$ depth $<2500$, a probability of site mutation $95 \%$, and every SNP loci separated by at least $5 \mathrm{bp}$, we obtained high confidence SNPs.

Bin maps were constructed using a sliding window approach. The SNPs were used as genomic markers, from which another type of genomic marker, i.e., bin marker were derived. The genomic bin markers were constructed using a slightly modified sliding-window approach developed by Huang et al. [73] based on the SNP dataset without imputation. Consecutive SNPs were scanned with a window size of 15 SNPs and a step size of one SNP. Windows with 11 or more SNPs from either parent were considered to be homozygous but those with fewer SNPs from a single parent were considered heterozygous. Recombination breakpoints were determined by the SNP position that switched one genotype to another consecutive genotype. Consecutive intervals of $30-\mathrm{kb}$ that do not possess any recombination event within the population were combined into bins, and these bins were used as markers. According to the breakpoint information, the bin information was generated using a PERL script [74]. The linkage maps of bin markers were constructed for each of the two RIL populations using JoinMap 4.0 [75].

\section{Data analysis and QTL mapping analysis}

Descriptive statistics like mean, standard deviation (SD), maximum and minimum trait value, coefficient of variation $(\mathrm{CV} \%)$, analysis of variance (ANOVA) and heritability for each seed germination-related trait, and correlations among pairs of traits were calculated using the SPSS17.0 software (http://www.spss.com).

The QTL analysis was performed on WinQTLCart2.5 software with the model of composite interval mapping [76]. A 10-cM window at a walking speed of $1 \mathrm{cM}$ was used in a stepwise forward regression procedure. The
LOD threshold was calculated using 1000 permutations for an experimental-wise error rate of $P=0.05$. The additive effects (Add) and phenotypic variance explained by QTL $\left(R^{2}\right)$ were estimated according to the bin at the highest peaks as determined by WinQTLCart2.5. The QTL was named following normal nomenclature [77].

\section{Candidate gene prediction}

Soybean genomic data from the physical interval position of "QTL hotspot A" and "QTL hotspot B" were downloaded from the SoyBae (http://www.soybase.org) and Phytozome (http://phytozome.jgi.doe.gov) database, and candidate genes were predicted based on the gene annotations information (http://www.soybase.org; https://phytozome.jgi.doe.gov). Candidate genes were screened by using the gene ontology (GO) information from SoyBase through online resources: GeneMania (http://genemania.org/), Gramene (http://archive.gramene.org/db/ontology), Kyoto Encyclopedia of Genes and Genomes website (KEGG, www.kegg.jp) and National Center for Biotechnology Information (NCBI: https://www.ncbi.nlm.nih.gov).

\section{Additional files}

Additional file 1: Figure S1. Frequency distribution of germination rate $(G R)$, normal seedling length $(S L)$ and normal seedling fresh weight (FW) of LM6 and ZM6 RIL populations under natural and artificial aging conditions. For natural aging only treatment trait were used for analysis, whereas for artificial aging both treatment and relative trait value have been used for analysis. Relative germination rate (rGR); Relative normal seedling length ( $r S L)$; Relative normal seedling fresh weight ( $r F W$ ). (DOCX $173 \mathrm{~kb})$

Additional file 2: Table S1. Distribution of SNPS, recombination bins and markers mapped on soybean chromosomes/linkage groups of LM6 RIL population. Bin-map (RAD-sequencing). Table S2. Distribution of SNPs, recombination bins and markers mapped on soybean chromosomes/linkage groups of ZM6 RIL population. Bin-map (RAD-sequencing). Table S3. Possible candidate genes predicted within "QTL hotspot A" and "QTL hotspot B" regions for soybean seed storability based on known functional annotations (XLSX $21 \mathrm{~kb}$ )

\section{Abbreviations}

(rFW): Relative normal seedling fresh weight; $(\mathrm{rGR})$ : Relative germination rate; $(\mathrm{rSL})$ : Relative normal seedling length; AA: Artificial aging; ANOVA: Analysis of variance; Chr: Chromosome; CV: Coefficient of variation; FW: Normal seedling fresh weight; GR: Germination rate; MAB: Marker-assisted breeding; MSG: Multiplexed shotgun genotyping; PV: Phenotypic variance; QTL: Quantitative trait loci; $R^{2}$ : Coefficient of determination; $\mathrm{RH}$ : Relative humidity; RIL: Recombinant inbred line; SD: Standard deviation; SL: Normal seedling length; SNP: Single nucleotide polymorphism

\section{Acknowledgements}

The authors thank the reviewers for comments that significantly improve the paper. We also thank National Center for Soybean Improvement (Ministry of Agriculture), Nanjing Agricultural University, Nanjing, China, for providing soybean germplasm.

\section{Authors' contributions}

TJZ and JAB conceived and designed the experiments. XZ, AH, SS, JJK performed the experiments. $X Z, A H, S S, J J K, J A B$ analyzed the data. $X Z$ and 
JAB drafted the manuscript. TJZ, JAB revised the paper. All authors have read and approved the final manuscript.

\section{Funding}

This work was supported by grants from the National Key R \& D Program of China (2018YFD0201006), the National Natural Science Foundation of China (Grant Nos. 31571691 and 31871646), the MOE Program for Changjiang Scholars and Innovative Research Team in University (PCSIRT_17R55), the Fundamental Research Funds for the Central Universities (KYT201801), the Jiangsu Collaborative Innovation Center for Modern Crop Production (JCIC-MCP) Program.

\section{Availability of data and materials}

The data sets supporting the results of this study are included in the manuscript. Soybean seeds are available from the National Center for Soybean Improvement, Nanjing Agricultural University, PR China.

\section{Ethics approval and consent to participate}

All the plant materials used in the current study were collected from the Soybean Germplasm Gene Bank at National Center for Soybean Improvement (Ministry of Agriculture), Nanjing Agricultural University, Nanjing, China, which are public and available for non-commercial purpose. No specific permits were required for the field studies described here. The study area is not privately owned or protected in any way, and the field studies did not involve endangered or protected species. Experimental researches on this study comply with institutional, national and international guidelines.

\section{Consent for publication}

Not applicable.

\section{Competing interests}

The authors declared that they have no competing interests.

Received: 6 November 2018 Accepted: 11 June 2019

Published online: 17 June 2019

\section{References}

1. Zhou Z, Jiang Y, Wang Z, Gou Z, Lyu J, Li W, Yu Y, Shu L, Zhao Y, Ma Y, Fang C, Shen Y, Liu T, Li C, Li Q, Wu M, Wang W, Wu Y, Dong Y, Wan W, Wang X, Ding Z, Gao Y, Xiang H, Zhu B, Lee S, Wang W, Tian Z. Resequencing 302 wild and cultivated accessions identifies genes related to domestication and improvement in soybean. Nat Biotechnol. 2015;33:408-14.

2. Schulte LA, Niemi J, Helmers MJ, Liebman M, Arbuckle JG, James DE, Kolka RK, O'Neal ME, Mark D, Tomer MD, Tyndall JC, Asbjornsen H, Drobney P, Neal J, Ryswyk GV, Witte C. Prairie strips improve biodiversity and the delivery of multiple ecosystem services from corn-soybean croplands. Proc Natl Acad Sci USA. 2017;114:11247-52.

3. Chen WH, Yang SH, Li ZH, Zhang XX, Sui XH, Wang ET, Chen WF. Ensifer shofinaesp. nov., a novel rhizobial species isolated from root nodules of soybean (Glycine max). Sys App Microbiol. 2017;40(3):144-9.

4. Yang F, Wang X, Liao D, Lu F, Gao R, Liu W, Yong T, Wu X, Du J, Liu J, Yang $W$. Yield response to different planting geometries in maize-soybean relay strip intercropping systems. Agron J. 2015;107(1):296-304.

5. Rubio de Casas R, Willis CG, Pearse WD, Baskin CC, Baskin JM, CavenderBares J. Global biogeography of seed dormancy is determined by seasonality and seed size: a case study in the legumes. New Phytol. 2017; 214(4):1527-36.

6. Shu K, Zhang H, Wang S, Chen M, Wu Y, Tang S, Liu C, Feng Y, Cao X, Xie $Q$. ABI4 regulates primary seed dormancy by regulating the biogenesis of abscisic acid and gibberellins in Arabidopsis. PLoS Genet. 2013;9(6): e1003577.

7. Bewley JD. (1997). Seed germination and dormancy. Plant Cell. 1997;9(7): 1055-66.

8. Eastmond PJ, Astley HM, Parsley K, Aubry S, Williams BP, Menard GN, Hibberd JM. Arabidopsis uses two gluconeogenic gateways for organic acids to fuel seedling establishment. Nat Commun. 2015;6:6659.

9. Chen $\mathrm{M}$, Thelen JJ. The plastid isoform of triose phosphate isomerase is required for the postgerminative transition from heterotrophic to autotrophic growth in Arabidopsis. Plant Cell. 2010;22(1):77-90.

10. Nguyen HT, Park H, Koster KL, Cahoon RE, Nguyen HT, Shanklin J, Clemente $\mathrm{TE}$, Cahoon EB. Redirection of metabolic flux for high levels of omega-7 monounsaturated fatty acid accumulation in Camelina seeds. Plant Biotechnol J. 2015;13(1):38-50.

11. Usha TN, Dadlani M. Evaluation of seed vigour in soybean (Glycine max). Agric Res Commun Cent J. 2015;38(3):308-12.

12. Hang NT, Lin Q, Liu L, Liu X, Liu S, Wang W, Li L, He N, Liu Z, Jiang L, Wan J. Mapping QTLs related to rice seed storability under natural and artificial aging storage conditions. Euphytica. 2015;203(3):673-81.

13. Han Z, Ku L, Zhang Z, Zhang J, Guo S, Liu H, Zhao R, Ren Z, Zhang L, Su H, Dong L, Chen Y. QTLs for seed vigor-related traits identified in maize seeds germinated under artificial aging conditions. PLoS One. 2014;9(3):e92535.

14. Börner A, Nagel M, Agacka-Mołdoch M, Gierke PU, Oberforster M, Albrecht T, Mohler V. QTL analysis of falling number and seed longevity in wheat (Triticum aestivum L.). J Appl Genet. 2018;59(1):35-42.

15. Dargahi $H$, Tanya $P$, Srinives $P$. Mapping of the genomic regions controlling seed storability in soybean (Glycine max L.). J Genet. 2014;93(2):365-70.

16. Justice OL, Bass LN. Principles and practices of seed storage (no. 04; USDA, SB118. 4 J8.). Washington, DC: US Department of Agriculture; 1978.

17. Dhakal KH, Jung KH, Chae JH, Shannon JG, Lee JD. Variation of unsaturated fatty acids in soybean sprout of high oleic acid accessions. Food Chem. 2014;164:70-3.

18. Li QT, Lu X, Song QX, Chen HW, Wei W, Tao JJ, Bian XH, Shen M, Ma B, Zhang WK. Selection for a zinc-finger protein contributes to seed oil increase during soybean domestication. Plant Physiol. 2017;173:2208-24.

19. Teng W, Li W, Zhang Q, Wu D, Zhao X, Li H, Han Y, Li W. Identification of quantitative trait loci underlying seed protein content of soybean including main, epistatic, and QTL x environment effects in different regions of Northeast China. Genome. 2017;60:649-55.

20. Barros JAS, Cavalcanti JHF, Medeiros DB, Nunes-Nesi A, Avin-Wittenberg T, Fernie AR, Araujo WL. Autophagy deficiency compromises alternative pathways of respiration following energy deprivation in Arabidopsis thaliana. Plant Physiol. 2017;175:62-76.

21. Munz E, Rolletschek H, Oeltze-Jafra S, Fuchs J, Guendel A, Neuberger T, Ortleb S, Jakob PM, Borisjuk L. A functional imaging study of germinating oilseed rape seed. New Phytol. 2017;216(4):181-1190.

22. Fleming MB, Richards CM, Walters C. Decline in RNA integrity of dry-stored soybean seeds correlates with loss of germination potential. J Exp Bot. 2017;68:2219-30.

23. Shelar VR, Shaikh RS, Nikam AS. Soybean seed quality during storage: a review. Agric Rev. 2008;29(2):125-31.

24. Shen H, Moon J, Huq E. PIF1 is regulated by light-mediated degradation through the ubiquitin-26S proteasome pathway to optimize seedling photomorphogenesis in Arabidopsis. Plant J. 2005:44:1023-35.

25. Singh RK, Ram HH. Inheritance study of soybean seed storability using an accelerated aging test. Field Crop Res. 1986;13:89-98.

26. Kang S, Eltahir EA. North China plain threatened by deadly heatwaves due to climate change and irrigation. Nat Commun. 2018;9(1):2894.

27. Singh RK, Raipuria RK, Bhatia VS, Rani A, Husain SM, Chauhan D, Chauhan GS, Mohapatra T. SSR markers associated with seed longevity in soybean. Seed Sci Tech. 2008;36(1):162-7.

28. Zeng DL, Guo LB, Xu YB, Yasukumi K, Zhu LH, Qian Q. QTL analysis of seed storability in rice. Plant Breed. 2006;125(1):57-60.

29. Bueso E, Muñoz-Bertomeu J, Campos F, Brunaud V, Martínez L, Sayas E, Ballester P, Yenush L, Serrano R. Arabidopsis thaliana HOMEOBOX25 uncovers a role for gibberellins in seed longevity. Plant Physiol. 2014;164:999-1010.

30. Schwember AR, Bradford KJ. Quantitative trait loci associated with longevity of lettuce seeds under conventional and controlled deterioration storage conditions. J Exp Bot. 2010;61(15):4423-36.

31. Zuo J, Liu J, Gao F, Yin G, Wang Z, Chen F, Li X, Xu J, Chen T, Li L, Li Y, Xia X, Cao H, Li Y. Genome-wide linkage mapping reveals qtls for seed vigor-related traits under artificial aging in common wheat (Triticum aestivum). Front Plant Sci. 2018:9:1101.

32. Nagel M, Rosenhauer M, Willner E, Snowdon RJ, Friedt W, Börner A. Seed longevity in oilseed rape (Brassica napus L.)-genetic variation and QTL mapping. Plant Genet Resour. 2011;9(2):260-3.

33. Nooshabadi SJY, Mashayekhi F. Enzyme activity and seedling growth of soybean seeds under accelerated aging. J Stress Physiol Biochem. 2013;9:4.

34. Mali MS, Shelar VR, Deepak RN. Effect of accelerated ageing on seed storage potential of soybean [Glycine max (L.) Merill]. J Food Leg. 2014;27(3):192-6.

35. Sasaki K, Fukuta Y, Sato T. Mapping of quantitative trait loci controlling seed longevity of rice (Oryza sativa L.) after various periods of seed storage. Plant Breed. 2005;124(4):361-6.

36. Li LF, Lin QY, Liu SJ, Liu X, Wang WY, Hang NT, Liu F, Zhao ZG, Jiang L, Wan J. Identification of quantitative trait loci for seed storability in rice (Oryza sativa L). Plant Breed. 2012;131:739-43. 
37. Fabrizius E, TeKrony D, Egli DB, Rucker M. Evaluation of a viability model for predicting soybean seed germination during warehouse storage. Crop Sci. 1999;39(1):94-201.

38. Nkang A, Umho EO. Six month storability of five soybean cultivars as influenced by stage of harvest, storage temperature and relative humidity. Seed Sci Technol. 1996;25:93-9.

39. Specht CE, Keller ER, Freytag U. Survey of seed germinability after long-term storage in the Gatersleben genebank. Plant Genet Resour Newsletter. 1997;111:64-8.

40. Xue Y, Zhang SQ, Yao QH, Peng RH, Xiong AS, Li X, Zha DS. Identification of quantitative trait loci for seed storability in rice (Oryza sativa L.). Euphytica. 2008;164(3):739-44.

41. Gutierrez-Gonzalez JJ, Vuong TD, Zhong R, Yu O, Lee JD, Shannon G, Sleper DA. Major locus and other novel additive and epistatic loci involved in modulation of isoflavone concentration in soybean seeds. Theor Appl Genet. 2011;123(8):1375-85.

42. Zou G, Zhai G, Feng Q, Yan S, Wang A, Zhao Q, Shao J, Zhang Z, Zou J, Han B. Identification of QTLs for eight agronomically important traits using an ultra-highdensity map based on SNPs generated from high-throughput sequencing in sorghum under contrasting photoperiods. J Exp Bot. 2012;63:5451-62

43. Rajjou L, Debeaujon I. Seed longevity: survival and maintenance of high germination ability of dry seeds. Comptes Rendus Biologies. 2008;331(10):796-805.

44. Miura K, Lin SY, Yano M, Nagamine T. Mapping quantitative trait loci controlling seed longevity in rice (Oryza sativa L.). Theor Appl Genet. 2002;104:981-6.

45. Powell AA, Matthews S, Oliveira MDA. Seed quality in grain legumes. Adv Appl Biol. 1984;10:217-85

46. Gan R, Min P, Jiang TW, Guo XC, Zhong XY. QTL associated with seed aging in rice. Acta Agro Sin. 2005;31:183-7.

47. Likhatchev BS, Zelensky GV, Kiashko YG, Shevchenko ZN. Modelling of seed ageing. Seed Sci Technol. 1984;12:385-93.

48. Rajjou L, Lovigny Y, Groot SP, Belghazi M, Job C, Job D. Proteome-wide characterization of seed aging in Arabidopsis: a comparison between artificial and natural aging protocols. Plant Physiol. 2008;148(1):620-41.

49. Liu N, Li M, Hu X, Ma Q, Mu Y, Tan Z, Xia Q, Zhang G, Nian H. Construction of high-density genetic map and QTL mapping of yield-related and two quality traits in soybean RILs population by RAD-sequencing. BMC Genomics. 2017;18(1):466.

50. Wang J, Chen P, Wang D, Shannon G, Zeng A, Orazaly M. Identification and mapping of stable QTL for protein content in soybean seeds. Molecular Breed. 2015;35(3):1-10

51. Priolli RHG, Campos JB, Stabellini NS, Pinheiro JB, Vello NA. Association mapping of oil content and fatty acid components in soybean. Euphytica. 2015;203(1):83-96.

52. Copley TR, Duceppe MO, O'Donoughue LS. Identification of novel loci associated with maturity and yield traits in early maturity soybean plant introduction lines. BMC Genomics. 2018;19(1):167.

53. Sonah H, O'Donoughue L, Cober E, Rajcan I, Belzile F. Identification of loci governing eight agronomic traits using a GBS-GWAS approach and validation by QTL mapping in soya bean. Plant Biotechnol J. 2015;13(2):211-21.

54. Fang C, Ma Y, Wu S, Liu Z, Wang Z, Yang R, Pan Y. Genome-wide association studies dissect the genetic networks underlying agronomical traits in soybean. Genome Biol. 2017;18(1):161.

55. Dhanapal AP, Ray JD, Smith JR, Purcell LC, Fritschi FB. Identification of novel genomic loci associated with soybean shoot tissue macro-and micronutrient concentrations. Plant Genome. 2018;11(2):1-21.

56. Ray JD, Dhanapal AP, Singh SK, Hoyos-Villegas V, Smith JR, Purcell LC, Fritschi FB. Genome-wide association study of ureide concentration in diverse maturity group IV soybean [Glycine max (L.) Merr.] accessions. G3. 2015. https://doi.org/10.1534/g3.115.021774.

57. Ooms JJ, Wilnier JA, Karssen CM. Carbohydrates are not the sole factor determining desiccation tolerance in seeds of Ambidopsis thaliana. Physiol Plant. 1994;90(3):431-6

58. Clerkx EJ, Blankestijn-De Vries H, Ruys GJ, Groot SP, Koornneef M. Genetic differences in seed longevity of various Arabidopsis mutants. Physiol Plant. 2004;121(3):448-61.

59. Sugliani M, Rajjou L, Clerkx EJ, Koornneef M, Soppe WJ. Natural modifiers of seed longevity in the Arabidopsis mutants abscisic acid insensitive3-5 (abi3-5) and leafy cotyledon 1-3 (lec1-3). New Phytol. 2009;184(4):898-908.

60. Shaheb MR, Islam MN, Nessa A, Hossain MA. Effect of harvest times on the yield and seed quality of French bean. SAARC J Agric. 2015;13(1):1-13.

61. Singh J, Paroha S, Mishra RP. Factors affecting oilseed quality during storage with special reference to soybean (Glycine max) and Niger (Guizotia abyssinica) seeds. Int J Curr Microbiol App Sci. 2017;6(10):2215-26.
62. Johnson RR, Wax LM. Relationship of soybean germination and vigor tests to field performance. Agron J. 1978;70(2):273-8.

63. Said Jl, Lin Z, Zhang X, Song M, Zhang J. A comprehensive meta QTL analysis for fiber quality, yield, yield related and morphological traits, drought tolerance, and disease resistance in tetraploid cotton. BMC Genomics. 2013;14(1):776.

64. Zhang Z, Li J, Muhammad J, Cai J, Jia F, Shi Y, Ge Q. High resolution consensus mapping of quantitative trait loci for fiber strength, length and micronaire on chromosome 25 of the upland cotton (Gossypium hirsutum L. ). PLoS One. 2015;10(8):e0135430.

65. Zhang X, Xu MG, Hina A, Kong JJ, Gai JY, He XH, Zhao TJ. Seed storability of summer-planting soybeans under natural and artificial aging conditions. Leg Res. 2019. https://doi.org/10.18805/LR-404.

66. Vijayakumar HP, Vijayakumar A. Standardization of accelerated ageing duration to evaluate seed storability of soybean cultivars. Int J Agric Sci Res. 2015;5(4):93-8.

67. Zhang ZH, Yu SB, Yu T. Mapping quantitative trait loci (QTLs) for seedlingvigor using recombinant inbred lines of rice (Oryza sativa L.). Field Crop Res. 2005;91(2):161-70.

68. Zhang WK, Wang YJ, Luo GZ, Zhang JS, He CY, Wu XL, Chen SY. QTL mapping of ten agronomic traits on the soybean (Glycine max L. Merr.) genetic map and their association with EST markers. Theor Appl Genet. 2004;108(6):1131-9.

69. Baird NA, Etter PD, Atwood TS, Currey MC, Shiver AL, Lewis ZA. Rapid SNP discovery and genetic mapping using sequenced RAD markers. PLoS One. 2008;3:e3376.

70. Andolfatto P, Davison D, Erezyilmaz D, Hu TT, Mast J, Sunayama-Morita T. Multiplexed shotgun genotyping for rapid and efficient genetic mapping. Genome Res. 2011;21:610-7.

71. Li R, Yu C, Li Y, Lam TW, Yiu SM, Kristiansen K. (2009). SOAP2: an improved ultrafast tool for short read alignment. Bioinformatics. 2009;25:1966-7.

72. Yi X, Liang Y, Huerta-Sanchez E, Jin X, Cuo ZX, Pool JE. Sequencing of 50 human exomes reveals adaptation to high altitude. Science. 2010;329:75-8.

73. Huang X, Feng Q, Qian Q, Zhao Q, Wang L, Wang A. High-throughput genotyping by whole-genome resequencing. Genome Res. 2009;19:1068-76.

74. Peng Y, Hu Y, Mao B, Xiang H, Shao Y, Pan Y, Sheng X, Li Y, Ni X, Xia Y, Zhang G, Yuan L, Quan Z, Zhao B. Genetic analysisfor rice grain quality traits in the YVB stable variant line using RAD-seq. Mol Genet Genomics. 2016;291:297-307.

75. Van Ooijen JW. JoinMap ${ }^{\bullet}$ 4, software for the calculation of genetic linkage maps in experimental populations. Kyazma BV,Wageningen 2006; 2006.

76. Wang S, Basten CJ, Zeng ZB. (2012). Windows QTL cartographer 2.5. Department of Statistics, North Carolina State University, Raleigh, NC. 2012. http://statg en.ncsu.edu/qtlcart/WQTLCart.htm.

77. McCouch SR, Chen X, Panaud O, Temnykh S, Xu Y, Cho YG, Huang N, Ishii T, Blair M. Microsatellite marker development, mapping and applications in rice genetics and breeding. Plant Mol Biol. 1997;35:89-99.

\section{Publisher's Note}

Springer Nature remains neutral with regard to jurisdictional claims in published maps and institutional affiliations.

Ready to submit your research? Choose BMC and benefit from:

- fast, convenient online submission

- thorough peer review by experienced researchers in your field

- rapid publication on acceptance

- support for research data, including large and complex data types

- gold Open Access which fosters wider collaboration and increased citations

- maximum visibility for your research: over $100 \mathrm{M}$ website views per year

At BMC, research is always in progress.

Learn more biomedcentral.com/submission 